\title{
Показывая путь: вклад наиболее новых членов НАТО
}

\author{
Пьотр Гавличек*
}

\section{Введение}

Определение символических пунктов поворота целенаправленного вклада Польши в Программы совершенствования образования в сфере обороны НАТО (ПСОСО) является сложной задачей. ${ }^{1}$ Для начала, надо упомянуть Двенадцатую ежегодную конференцию Консорциума ПРМ военных академий и институтов, занимающихся исследованиями в сфере обороны. Польша имела удовольствие быть хозяином этой встречи в Варшаве в июне 2010 года и приветствовать большую группу представителей военных академий, институтов, занимающихся исследованиями в сфере обороны, министров обороны и министров иностранных дел, а также и других институтов, занимающихся вопросами безопасности.

Для многих представителей Польши, и в частности, Национального университета обороны в Варшаве, эта конференция предоставила возможность подтвердить важность создания сетей специалистов по образованию, людей, определяющих политику, и практиков - с целью развивать эффективную систему образования в сфере обороны. Во время дебатов и дискуссий в рамках конференции было подчеркнуто, что Консорциум ПРМ - как ключевая сеть, которая связывает прак-

\footnotetext{
Пьотр Гавличек, капитан первого ранга в отставке, является доцентом Национального университета обороны Польши в Варшаве. Он так же представитель по инновациям и директор канцелярии ректора-начальника. Его исследования и преподавательская работа лежат в области дистанционного обучения, военной стратегии, асимметричных угроз, совместных операций, лидерства и Болонского процесса. Он является членом многих международных исследовательских и образовательных органов, в том числе: (1) редакционного совета ежеквартального журнала Консорциума ПРМ «Взаимосвязи»; (2) рабочей группы НАTO по дистанционному обучению - NTGTG WG ED \& IT; (3) рабочей группы по дистанционному обучению Консорциума ПРМ; (4) редакционного совета рецензированного журнала «Оборона и стратегия». Он так же причастен к работе странпартнеров Консорциума ПРМ по Программам совершенствования образования в сфере обороны (ПСОСО).

1 Программа совершенствования образования в сфере обороны была создана в 2006 году для реализации инициативы Альянса укрепить оборонные институты в определенных странах-партнерах с тем, чтобы обеспечить гражданский и демократический контроль вооруженных сил. Главной целью программы является развитие и реформирование образования в сфере обороны. Это включает такие виды деятельности как подготовка программ и методологий для преподавания или проведения исследований. Эта деятельность координируется представителями Международного секретариата (МС) и государства, которое приняло на себя ведущую роль в конкретном проекте, в сотрудничестве с Международным военным секретариатом (МBC), Союзным командованием по трансформации, школой НАТО в Обераммергау, Колледжем обороны НАТО в Риме и Европейским командованием НАТО. Существует общий фонд ресурсов НАТО и Министерства обороны США (фонд «Варшавская инициатива»), который финансирует эту деятельность.
} 
тиков в сфере обороны в Европе и Центральной Азии - напрямую способствует установлению лучшего понимания проблем безопасности, и в результате, укреплению безопасности обществ стран-членов. Встреча так же дала участникам возможность понять и поделиться своими схожими восприятиями безопасности. В итоге был сделан вывод, что такое «общее» восприятие может быть достигнуто и гарантировано только в результате образования, основанного на общем фундаменте. Что касается Польши, было очевидно, что Варшава является самым подходящим местом для такой дискуссии, а НУО - самой подходящей институцией для прямого участия.

\section{Почему путь должна показывать Польша?}

Польша успешно справилась с переходом к демократическому управлению после окончания Холодной войны, и в течение двадцати лет после распада Организации Варшавского договора пользовалась преимуществами демократии. Основным результатом сотрудничества Польши с внешними партнерами стало ее членство в ключевых европейских и евроатлантических институциях, в том числе в НАТО и Европейском союзе. Поэтому Польша может быть хорошим примером, которому могут следовать другие страны, находящиеся на начальных или промежуточных этапах процесса демократических трансформаций.

Военное образование, несомненно, является важным элементом современных вооруженных сил. Образованные и умелые солдаты составляют ядро вооруженных сил. Хорошо подготовленный персонал является важнейшим инструментом, в первую очередь, для сохранения мира. Вот почему сегодня понятие «образование и квалификация» следует понимать в самом широком контексте, особенно с учетом меняющегося характера среды безопасности. Эта среда начала быстро меняться с начала 1990-х, а в течение последних десяти лет изменения приобрели драматический характер. Мы сталкиваемся с совершенно новыми вызовами в таком количестве и в таком разнообразии, что просто невозможно определить все или хотя бы дать им наименования. Наша картина целостной среды безопасности размыта и туманна. И все-таки, с другой стороны, чтобы успешно справляться с этой реальностью, критически важно максимизировать эффективность процесса образования и квалификации. Образование должно готовить лидеров и развивать новые умения, и только эти подготовленные лидеры будут в состоянии вести корабль в изменчивом море проблем безопасности.

Поэтому Польша высоко ценит все действия, направленные на поощрение процесса реформ в образовании в сфере обороны в странах-партнерах. Эти инструменты помогают партнерам, в частности странам Южного Кавказа и Центральной Азии, ввести усовершенствованные стандарты образования в сфере обороны. ${ }^{2}$

2 Эксперты Национального военного университета принимают участие в мероприятиях ПСОСО (согласно соответствующей матрице) в основном в Армении (ДО, Болонский процесс, посылает лекторов по профессиональным военным темам); Азербайджане (ДО, Болонский процесс, принимает членов академического состава); Грузии (ДО, Болонский 
Следовательно, деятельность Консорциума ПРМ и НАТО способствует достижению основных целей инициативы «Партнерство ради мира»: обеспечению и развитию оперативной совместимости мышления.

\section{Почему путь должен прокладывать НУО?}

Национальный университет обороны Польши является необычным высшим учебным заведением. Несмотря на факт, что это университет вооруженных сил Польши, все большее количество гражданских лиц поступает туда на учебу. Поэтому, чтобы соответствовать всему спектру ожиданий, НУО ищет инновационные решения, в полной мере применяет принципы Болонского процесса и старается делиться ими. Есть военные и гражданские слушатели, чьи потребности, касающиеся форм обучения и квалификации, должны учитываться. С одной стороны, специфическая организационная структура университета (два факультета и три центра) обеспечивает традиционные модели обучения, а с другой стороны процесс образования и квалификации опирается на новую технологию и на инновационные решения. НУО пытается перейти от структуры, основанной на принципе обучения «что думать», к структуре, показывающей слушателям «как думать». С изменением характера проблем безопасности, рисков и угроз, возможности для эффективной реакции так же изменились. Процесс обучения и получения квалификации в Варшавском НУО обеспечивается современной технологией и инновационными системами. Это осуществляется таким способом, чтобы ключевые акторы в конфликтных областях, в частности военные акторы, были эффективно подготовлены к встрече с вызовами новой среды безопасности, в частности к тому, что касается культурологической осведомленности.

В таком контексте, в этой статье излагаются некоторые соображения относительно двух видов деятельности НУО в Варшаве, которые можно принять подходящими для подражания - примеры, в которых Польша и ее университет обороны прокладывают путь. Эти две области связанны с сущностью Болонского процесса в сфере военно-гражданских отношений и с развитием эффективного дистанционного обучения (ДО) в течение относительно короткого периода времени.

\section{Обмен опытом}

\section{Болонский процесс}

Применение принципов Болонского процесса потребовало от НУО в Варшаве получения аккредитации по Хартии университетов Эразмус. ${ }^{3}$ Получение этой аккредитации позволило НУО в Варшаве инициировать следующие виды деятельности:

процесс, поддержка процесса планирования и магистерских программ); Молдовы (ДО) и в Ираке (Болонский процесс).

3 Исполнительное Агентство по образованию, аудиовизуальным средствам и культуре (ИАОАВСК) в Брюсселе предоставило такие права университету 8 апреля 2009 года. 
1. Мобильность студентов на период обучения в партнирующем университете

2. Мобильность студентов для участия в практическом обучении в партнирующей компании, организации, институте повышения квалификации или исследовательском институте в другой стране, участвующей в программе

3. Мобильность академического состава для чтения лекций в партнирующем университете

4. Мобильность академического состава для повышения квалификации в академическом или неакадемическом институте в другой стране, участвующей в программе

5. Обмен студентами или преподавателями

6. Участие в таких проектах как Интенсивная программа (ИП).

Вся эта деятельность осуществляются по Программе «Эразмус» для обучения в течение всей жизни. Программа реализуется специальной группой, сфокусированной на следующих задачах:

1. Предпринятое шагов к интенсификации участия университета в программе «Эразмус», в том числе координирование стратегических решений, связанных с сотрудничеством с другими университетами

2. Внутренние мероприятия, направленные на расширение мобильности всего академического сообщества

3. Реализация задач международного сотрудничества, связанных с принятием иностранных преподавателей

4. Интегрирование университета в международные образовательные программы, проводимые под эгидой ЕС

5. Гарантирование полноценного использования получаемых грантов

6. Поддерживание двухсторонних отношений с партнирующими университетами

7. Мониторинг системы достижений и обеспечение их популяризации

8. Участие в организации интенсивных курсов

9. Стимулирование деятельности Европейской студенческой организации ССЭ (Студенческой сети «Эразмус») в университете.

Интернационализация деятельности НУО, которая осуществлялась посредством его участия в программе «Эразмус», позволила к концу 2011-2012 учебного года 127 сотрудникам и 184 студентам университета посетить партнирующие университеты. К 1 ноября 2012 года НУО подписал более пятидесяти соглашений с иностранными университетами и партнирующими институциями, касающихся различных форм двухстороннего сотрудничества, в том числе и программы мобильности. Деятельность по программе «Эразмус» постоянно развивается и, располагая финансированием в объеме 300000 евро, мы надеемся осуществить по 
крайней мере 200 мероприятий мобильности для преподавателей, студентов и административного персонала в 2012-2013 академическом году. В результате участия в программе «Эразмус», НУО занимает шестое место среди 73 университетов Варшавы по объему студенческой и преподавательской мобильности и тридцать четвертое среди 368 университетов Польши. Дополнительно, для того чтобы расширить международную деятельность университета, реализуются разнообразные проекты и гранты Европейского союза, в том числе интенсивный курс по авиационной безопасности (“IP LotSec”) для студентов из пяти стран и интенсивный курс польского языка по программе «Эразмус» (EILC) для тридцати студентов из двенадцати стран.

Особенно важным является расширение сотрудничества в сфере образования с военными университетами из соседних стран и стран Вишеградской четверки такими как Университет обороны Чешской Республики, Национальная академия обороны Словакии, Военная академия Литвы, Национальный университет государственной службы Венгрии и Немецкий университет вооруженных сил в Гамбурге. Кроме этих образовательных институций, есть множество как военных, так и гражданских организаций, расположенных по всей Европе, предоставляющих в случае необходимости возможность предпринимать и другие шаги в сотрудничестве.

\section{Дистанционное обучение}

При представлении картины деятельности по реализации дистанционного обучения (ДО) в НУО в Варшаве, важно начать с основных предположений, лежащих в основании этой деятельности, и показать начальные шаги создания эффективной системы дистанционного обучения. Мы можем идентифицировать следующие шаги:

1. Сбор информации об электронном/дистанционном обучении

2. Реализация концепции

3. Создание необходимых технических возможностей

4. Создание образовательного и квалификационного потенциала

5. Развитие необходимых человеческих ресурсов.

Необходимая информация может быть получена из множества источников, в том числе из книг, баз данных, опыта преподавателей или экспертов по конкретным вопросам. Эта информация пакуется, комбинируется в объекты, которые называются Единицами содержания (ЕС), и которые затем переносятся в систему управления обучением (СУО). Есть множество доступных СУО, в основном коммерческие, но есть и такие с открытым кодом, как например система ILIAS, кото- 
рую решил использовать НУО. ${ }^{4}$ Выбор подходящей СУО зависит от реальных потребностей и от типа институции. Следующий элемент, это средство доставки, что включает любые способы и средства доставки содержания, уже встроенного в СУО, потребителю, т.е. учащемуся. Это может быть веб-браузер, мобильные средства связи и т.п., и последним (но наиболее важным) элементом является потребитель, учащийся.

Рассматривая институциональную среду НУО в Варшаве, важно подчеркнуть, что развитие дистанционного обучения является весьма сложным процессом, особенно имея в виду то, что надо учитывать образовательные потребности. Итак, первый шаг, это необходимость разработать курс, встроить его в СУО, инициировать его, и что наиболее важно, поддерживать его, т.е. управлять им. Для дальнейшего развития идеи необходимо дефинировать, измерять, анализировать, управлять и усовершенствовать курсы, совершенно так же, как в любом процессе управления качеством. При разработке модели дистанционного обучения в НУО учитывались все эти соображения, и важно отметить, что эта модель весьма подобна тем, которые используются Международной сетью безопасности, Командованием НАТО по трансформации или Командованием объединенных сил НАТО. Благодаря тому, что CУO ILIAS является системой с отрытым кодом, стало возможным сэкономить около 50000 долларов США, которые были бы истрачены на оценки и сравнения. В результате этой самоотверженной работы НУО разработал множество курсов для вооруженных сил Польши, а также и для гражданских студентов.

Пытаясь определить направление будущих усилий, необходимо иметь в виду две основные области. Первая, это электронное обучение, включающее разные образовательные услуги, которые поддерживают аккредитированные согласно Болонскому процессу образовательные дорожки на уровне степени бакалавра, магистра и доктора. Второй областью является дистанционное обучение и мобильное дистанционное практическое обучение, которые должны включать весь спектр процессов обучения в течение всей жизни и состоят из коротких профессиональных курсов, предназначенных для удовлетворения потребностей вооруженных сил Польши. С точки зрения НУО, преимуществами дистанционного обучения являются: небольшая себестоимость подготовки, минимальные системные требования к устройствам, которыми пользуются потребители, наличие приложений и платформ с открытым кодом, поддержка со стороны внешних партнеров и расширение спектра образовательных услуг. Потенциальные риски и угрозы в основном связаны с техническими вопросами (менеджмент безопасности и систем, IT инфраструктура). Стимулирование преподавательского состава к использованию новых методов доставки знаний тоже стало для нас вызовом.

4 HУO в Варшаве является не только «потребителем» CУO ILIAS, но и «производителем». Член группы по дистанционному обучению НУО в Варшаве отвечает за интерфейс на польском языке CУO ILIAS, и инсталляция системы в НУО в Варшаве является одной из трех официально признанных инсталляций в Польше. 
Деятельность НУО в Варшаве по дистанционному обучению широко известна и встречает очень радушный прием в странах НАТО и Консорциума ПРМ. Члены польской группы по дистанционному обучению принимали участие в разных международных и национальных мероприятиях, в том числе конференциях, семинаpax и встречах, на которых главное внимание уделялось обмену опытом и распространению лучших практик. Эти встречи также дали возможность обсудить технические и методические детали и поделиться информацией о новинках в этой области. Конкретным примером такого подхода является Рабочая группа по дистанционному обучению Консорциума ПРМ. ${ }^{5}$

Дистанционное обучение может оказать очень сильную поддержку традиционному обучению. Оно особенно удобно для обучения в частях вооруженных сил, особенно в тех, что географически удалены. Кроме того, такое обучение можно использовать для повышения квалификации перед полевым обучением (как начальный курс или как предварительный курс). Дистанционное обучение так же нацелено на развитие таких качеств как уверенность в собственных силах, самодисциплина, умение распределять время и умение оценивать себя самого.

Ключом к успеху является человеческий фактор - выбор правильной команды, которая займется реализацией любого проекта, учитывая разные методологические аспекты. Только соответственно подготовленные учебные материалы привлекут студентов к участию в процессе обучения, увеличат их мотивацию и в результате, расширят их знания. Польские вооруженные силы придают большое значение деятельности по дистанционному обучению: каждый офицер или сержант ПВС, которому предстоит работать в структурах НАТО или ЕС, обязан пройти специальный курс ДО, организованный в НУО в Варшаве.

НУО в Варшаве можно рассматривать как пример того, как можно организовать эффективное ДО в течении не более чем года и при том «очень дешево». Основным фактором при применении такого инновационного подхода как ДО является индивидуальная мотивация и институциональная решимость стимулировать принципы электронного обучения. Если есть желание, средства найдутся: вот ответ на вопрос, как быть эффективным. Необходима самоотверженность, огонек и работа, но все компенсируется удовлетворением, которое мы испытываем, когда НУО в Варшаве приводится как пример для подражания в отношении организации электронного обучения.

\section{Выводы}

Союзники и партнеры смотрят положительно на усилия, направленные на поддержку образования в сфере обороны. Инициатива ПСОСО является важным элементом в обеспечении практической помощи участвующим странам-партнерам. Другим преимуществом является то, что работа в этом направлении не требует значительных расходов, ни со стороны партнеров, ни со стороны государств-до-

5 НУО в Варшаве будет хозяином встречи Рабочей группы по ДО в ноябре 2013 года. 
норов. Это позволяет рассматривать возможность расширения группы участвующих стран.

Роль Польши очевидна для всех, и ей дана высокая оценка экспертов, которые отмечают важность реформ в сфере военного образования в пост-советских государствах и которые принимают участие в таких мероприятиях. В настоящее время осуществляется восемь индивидуальных программ в Армении, Азербайджане, Грузии, Молдовы, Казахстане, Афганистане, Ираке и Мавритании. Несколько подобных мероприятий было организовано в Иордании и Албании. В большинстве этих случаев, ведущим государством являются Соединенные Штаты (кроме как для Армении, где ведущим государством является Канада). Реализация каждой программы в стране-партнере начинается ознакомительным визитом экспертов HATO, в том числе и из Объединенного командования по трансформации (ОКТ) и из стран-членов, которые заинтересованы в оказании поддержки реформам образования в сфере обороны. Вместе они работают над определением целей, вида перемен и плана действий, которые следует осуществить в течение трех лет. Каждый год проводится оценка текущей деятельности на предмет определения необходимого темпа и возможных усовершенствований.

Готовность Польши участвовать в такой деятельности является существенным элементом практической поддержки стран-партнеров. В этом смысле, при оценке институций, любые дальнейшие действия могут быть направлены на расширение ПСОСО в другие страны. Страны ПРМ ожидают от Альянса, что он будет в состоянии оказывать содействие и предоставлять экспертизу для осуществления таких программ, следовательно, необходимо продолжить инвестирование времени и ресурсов в оказании поддержки усилиям стран-партнеров, направленным на проведение реформ образования в сфере обороны.

Первая конференция функциональной клиринговой палаты для подведения итогов деятельности стран-доноров, участвующих в ПСОСО, состоялась в штабквартире НАТО в сентябре 2012 года. Такие мероприятия должны продолжаться, придавая инициативе более организованный и институциализированный характер в рамках деятельности НАТО. Конференция показала, что в этой области Польша является одной из самых активных стран. Встреча помогла затвердить факт, что Национальный университет обороны остается важным элементом сети, которая работает для укрепления образования в сфере обороны, и имеет существенный академический вклад в сферу безопасности. 6 Во время конференции первой клиринговой палаты были сделаны три предложения относительно проведения будущих мероприятий: Объединенным командованием по трансформации в Нор-

6 В этом смысле важно подчеркнуть, что в ноябре 2012 года НАТО приняло официальную заявку МО Украины на участие в ПСОСО. Оценочные визиты назначены на первый триместр 2013 года с целью подготовить индивидуальный план действий, который станет основой программы НАТО оценки коллег. Есть депонированное предложение Польского НУО участвовать в качестве академического соруководителя. 
фолке, штат Виржиния; Центром им. Джорджа К. Маршалла в Гармиш-Партенкирхене и Польским Национальным университетом обороны в Варшаве. ${ }^{7}$

Международное признание НУО в Варшаве как модели для подражания в применении инновационных подходов к образованию и квалификации приносит нам глубокое удовлетворение, так как является подтверждением усилий и готовности Польши вносить свой вклад в эту ключевую область. В эпоху уменьшающихся военных бюджетов, образование является лучшей инвестицией. Новые инструменты информационно-коммуникационных технологий и деятельности Болонского процесса не являются совсем «малобюджетными решениями», но фактически выбора нет. Если вам кажется, что образование стоит дорого, попробуйте оценить, сколько вам будет стоит невежество.

7 Было решено, что следующая сессия клиринговой палаты состоится в июне 2013 года в Норфолке. Следующая за ней в Гармиш-Партенкирхене в декабре 2013, а следующая за ней в Варшаве в 2014 году. 